\title{
Multi Criteria Framework for Surface Water Quality Management
}

\author{
Mohamed Ahmed Reda Hamed \\ Civil Engineering Department, Canadian International Colleague (CIC), Sheikh Zayed, Egypt \\ Email: moha_hamed@cic-cairo.com
}

How to cite this paper: Hamed, M.A.R. (2019) Multi Criteria Framework for Surface Water Quality Management. Journal of Environmental Protection, 10, 1032-1042. https://doi.org/10.4236/jep.2019.108061

Received: July 12, 2019

Accepted: August 18, 2019

Published: August 21, 2019

Copyright $\odot 2019$ by author(s) and Scientific Research Publishing Inc. This work is licensed under the Creative Commons Attribution International License (CC BY 4.0).

http://creativecommons.org/licenses/by/4.0/

\begin{abstract}
Edku Lake, the third largest in the system of the northern coastal wetlands in Egypt, situated on the west part of Nile Delta, is considered as an important fishing area in Egypt. The lake suffers from high levels of aquatic vegetation and from the expansion in fish farming and agricultural discharges. To solve lake water quality problems, the study aims to develop the multi-criteria analysis (MCA) framework capable of evaluating the proposed lake water quality improvement scenarios. The work tasks were divided into two phases. In the first phase, many proposed scenarios involved on primary, secondary, surface wetland, biological biofilm, and adding a new artificial inlet were proposed by applying Surface-water Modeling System (SMS) with two dimensional hydrodynamic. The second phase involved in developing the required hierarchical MCA based on an integrated technical, environmental, economic and socio-community indicators. The main results of MCA showed that the water quality management scenario focusing on combination of applying biological biofilm technique for drain effluents and also adding a new artificial inlet at the northern lake region can represent the optimum scenario for solving the lake water quality problems.
\end{abstract}

\section{Keywords}

Edku Lake, Hydrodynamic Model, SMS, MCA

\section{Introduction}

Edku Lake is a brackish lake which lies to the west of Rosetta Nile branch. A number of small islands divide the lake into a smaller western district and a larger one comprising the central and eastern parts where the outlets of Bersik at the south-central part of this lake [1]. The Lake is subjected to huge inputs of terrigenous and anthropogenic nutrients (especially phosphorus and nitrogen 
compounds) from agricultural runoff, sewage and drains discharges [2]. These nutritional conditions create rich resource spectrum for algal growth and make the lake biologically productive. Previous studies conducted on the hydrography, chemical and biological characteristics of Lake Edku concluded that this lake suffered from a high level of eutrophication due to the heavy load of nutrients, especially phosphorus [3].

Surface Water Modeling System (SMS) is a two-dimensional finite element hydrodynamic computer model developed by the Waterway Experimental Station of the U.S. Army Engineer Research and Development Center. SMS models the water surface elevation, flow velocity, contaminant transport and dispersion, sediment transport and deposition, subcritical-supercritical flow, and longshore waves for complex 2D horizontal flow problems [4].

Multi Criteria Analysis (MCA) identifies multiple criteria against which the study area water quality management scenarios can be evaluated and then compared to each other. MCA technique can be developed based on ranking and prioritizing the alternatives through technical, economical environmental and socio-cultural criteria.

\section{Study Area}

Edku Lake is a coastal wetland in the eastern Mediterranean and is located about $40 \mathrm{Km}$ eastern of Alexandria city and $18 \mathrm{Km}$ western of Rosetta branch of the River Nile. It is located west of the River Nile delta between longitudes $30^{\circ} 8^{\prime} 30^{\prime \prime} \mathrm{E}$ and $30^{\circ} 23^{\prime} \mathrm{E}$ and latitudes $31^{\circ} 10^{\prime} \mathrm{N}$ and $31^{\circ} 18^{\prime} \mathrm{N}$. The lake is connected to the adjacent Abu Qir Bay through Boughaz El Maadia. There are two main drains discharge their wastes into the lake; namely El-Khayry and Barsik drains. These drains are joined to three sources of drainage water coming from El-Bosely, Ed$\mathrm{ku}$ and Damanhour subdrains, which transport domestic, agriculture, and industrial wastewaters as well as the drainage water of fish farms [5].

\section{Materials and Methods}

\subsection{Data Requirements}

Surface water samples were collected from thirteen sampling locations of Edku Lake. The analyses of water samples were carried on various water quality parameters according to the standard methods for the examination of water and wastewater (APHA, 2012) during three consequence years $(2015,2016$, and 2017) to show the effect of the spatial and temporal variation. Figure 1 illustrates the selected sampling stations for Eudk Lake.

\subsection{Methods}

The available data of the Bathymetry Lake included hydrodynamic data like as (bed level elevations), meteorological (temperature), and geometrical (boundary lake coordinates), Water quality datasets used to create the bathymetry mesh model and in the calibration/validation process of hydrodynamic model, where 
the model also used to simulate the distributions of Electric Conductivity (EC), Dissolved Oxygen (DO), Biological Oxygen Demand (BOD), Ammonia $\left(\mathrm{NH}_{4}\right)$, and Phosphorus $\left(\mathrm{PO}_{4}\right)$. The coupled-hydrodynamic water quality models were utilized in assessing the mitigation scenarios aiming at enhancing the circulation patterns and controlling pollution inside the lake. Figure 2 illustrates the main parts of study methodology.

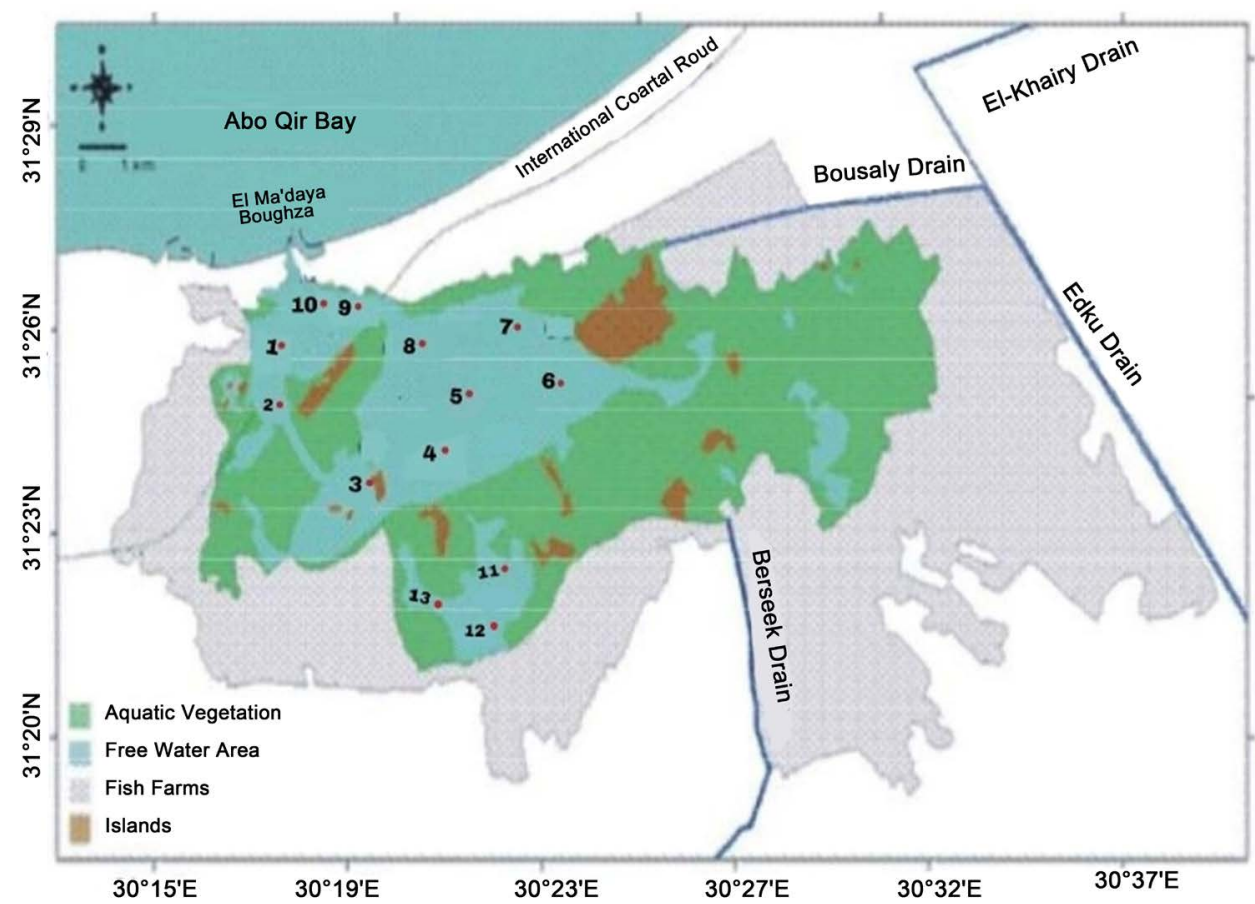

Figure 1. Selected sampling stations of Edku Lake.

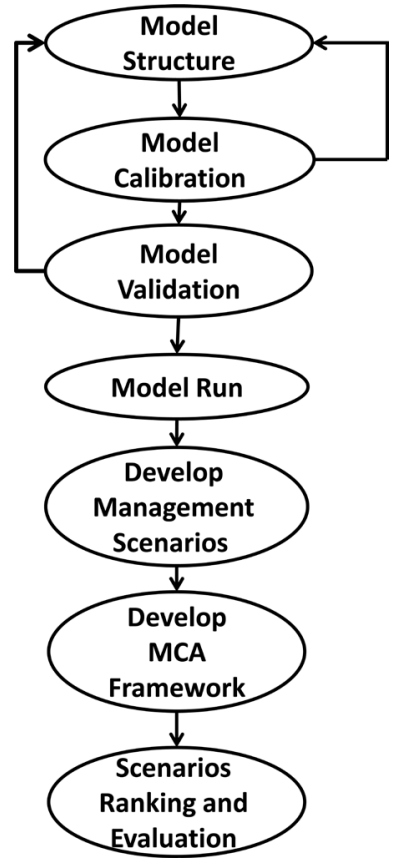

Figure 2. Study methodology layout. 


\section{Modeling Framework}

The generalized computer program SMS solves the depth-integrated equations of fluid mass and momentum conservation in two horizontal directions. The forms of the solved equations by the finite element method using the Galerkin method of weighted residuals [6].

\section{Results and Discussion}

\subsection{Model Calibration}

SMS Hydrodynamic model was calibrated by using 2015 data set in order to satisfy both of accuracy and stability for the simulated lake water quality results. The model was spatially calibrated against measured electric conductivity (EC) because it is considered a conservative material and it is an excellent water mass tracer. Figure 3 illustrates the lake simulated EC during January 2015, while Figure 4

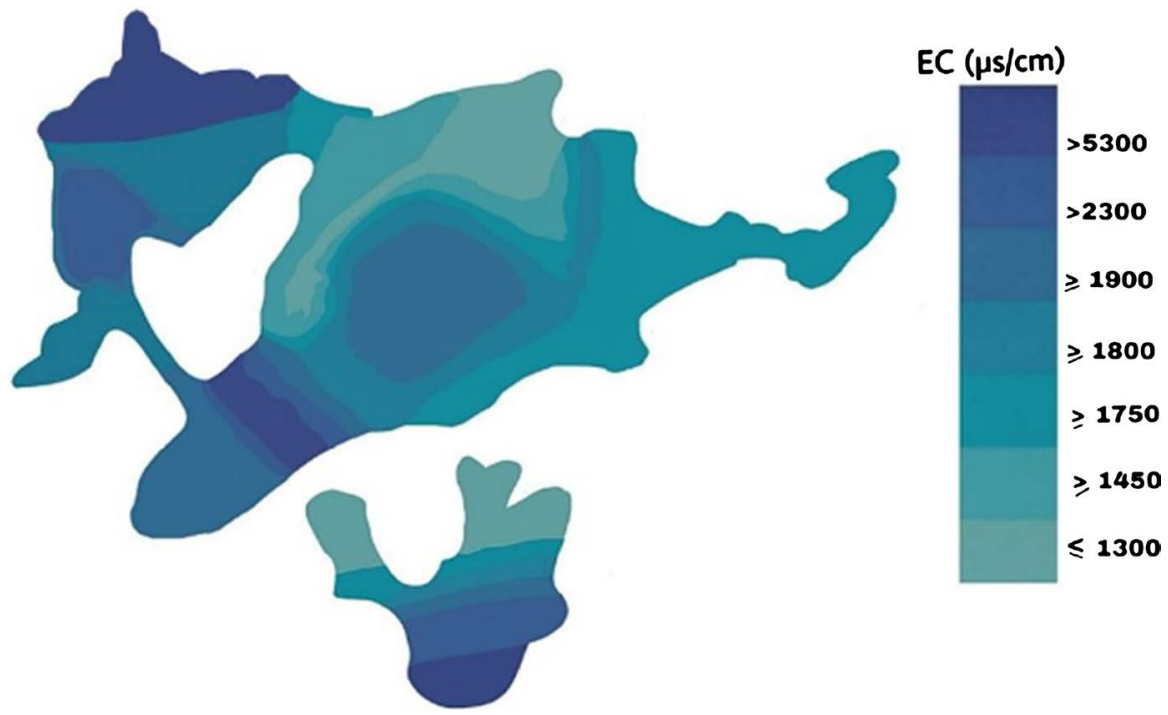

Figure 3. Edku Lake simulated EC ( $\mu \mathrm{S} / \mathrm{cm})$, January 2015.

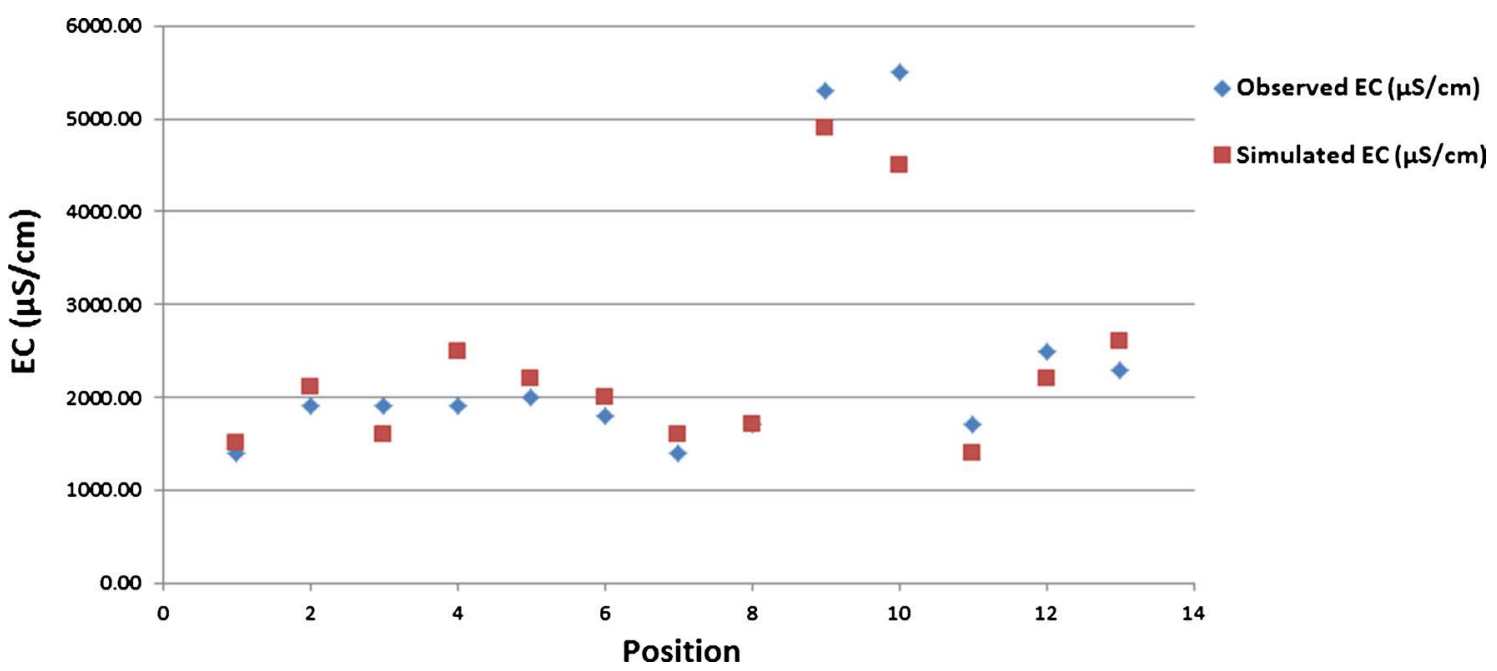

Figure 4. Edku Lake observed and simulated EC $(\mu \mathrm{S} / \mathrm{cm})$, January 2015. 
shows the simulated EC with respect to the corresponding observed lake EC.

From Figure 3 and Figure 4, according to applied statistical measures such as the relative means absolute error and correlation coefficient of determination $\left(R^{2}\right)$, it can be noted that the mean absolute error value is very small (0.29) and tends to be equal its optimal statistics value (Zero) for various simulated results. The model accuracy is further confirmed from high values (0.92) of $\mathrm{R}^{2}$ at the calibration points, so it is obvious that there is an excellent match of observed and modeled results at different sites of the study area.

\subsection{Model Run}

After calibration of SMS hydrodynamic model, the model was run by using water quality data for Year 2016.

\subsubsection{Modeling of Dissolved Oxygen}

Figure 5 illustrates the simulated DO results, while Figure 6 shows the simulated DO with the corresponding observed results.

It can be noted from Figure 5 and Figure 6 that the simulated DO results were strong correlated with the observed DO $\left(\mathrm{R}^{2}=0.91\right)$. There are variations in DO level in different lake locations due to the different pollution source locations. In many lake regions; DO level is less than $5 \mathrm{mg} / \mathrm{l}$ that can't satisfy permissible limits of the Egyptian national guidelines (law 48/1982), however, oxygen situation in this lake region is alarming.

\subsubsection{Modeling of Ammonia}

The spatial distribution of the simulated $\mathrm{NH}_{4}$ result is shown in Figure 7 while the simulated $\mathrm{NH}_{4}$ with the respect to observed $\mathrm{NH}_{4}$ concentration results are indicated in Figure 8.

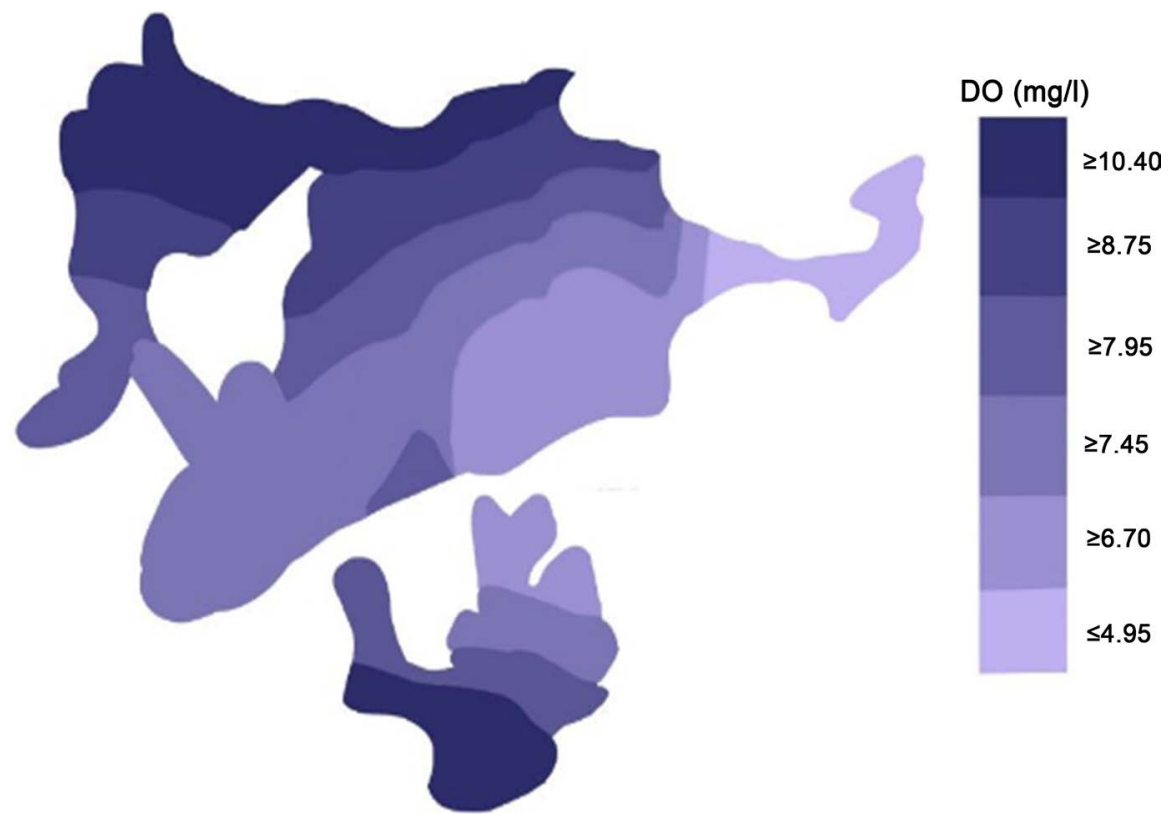

Figure 5. Edku Lake simulated DO spatial distribution, January 2016. 


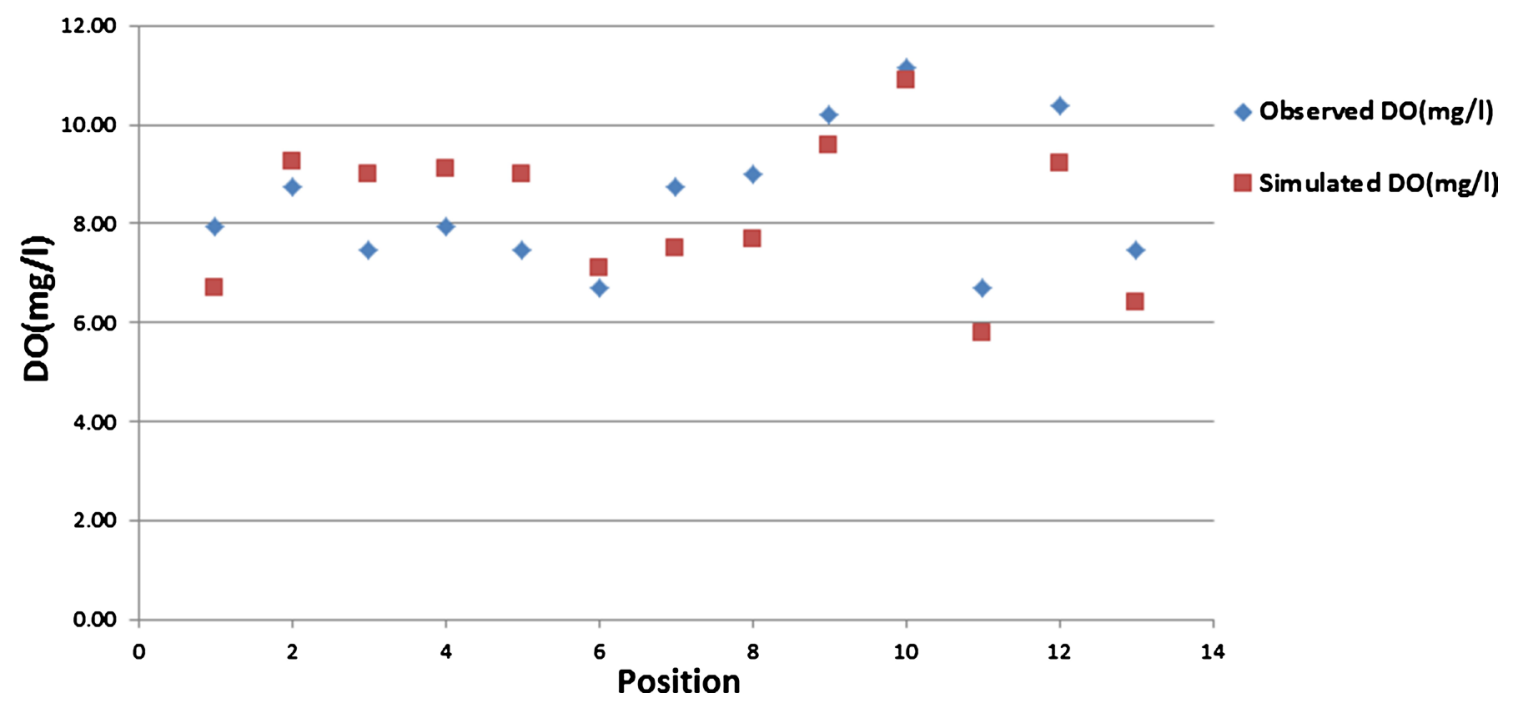

Figure 6. Edku Lake observed and simulated DO, January 2016.

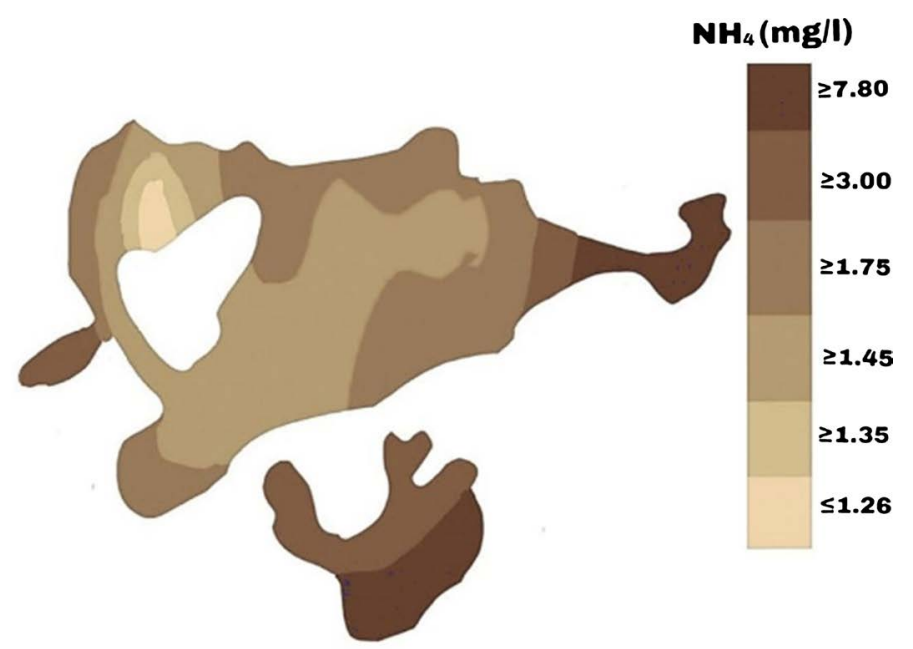

Figure 7. Edku Lake simulated $\mathrm{NH}_{4}$ spatial distribution, January 2016.

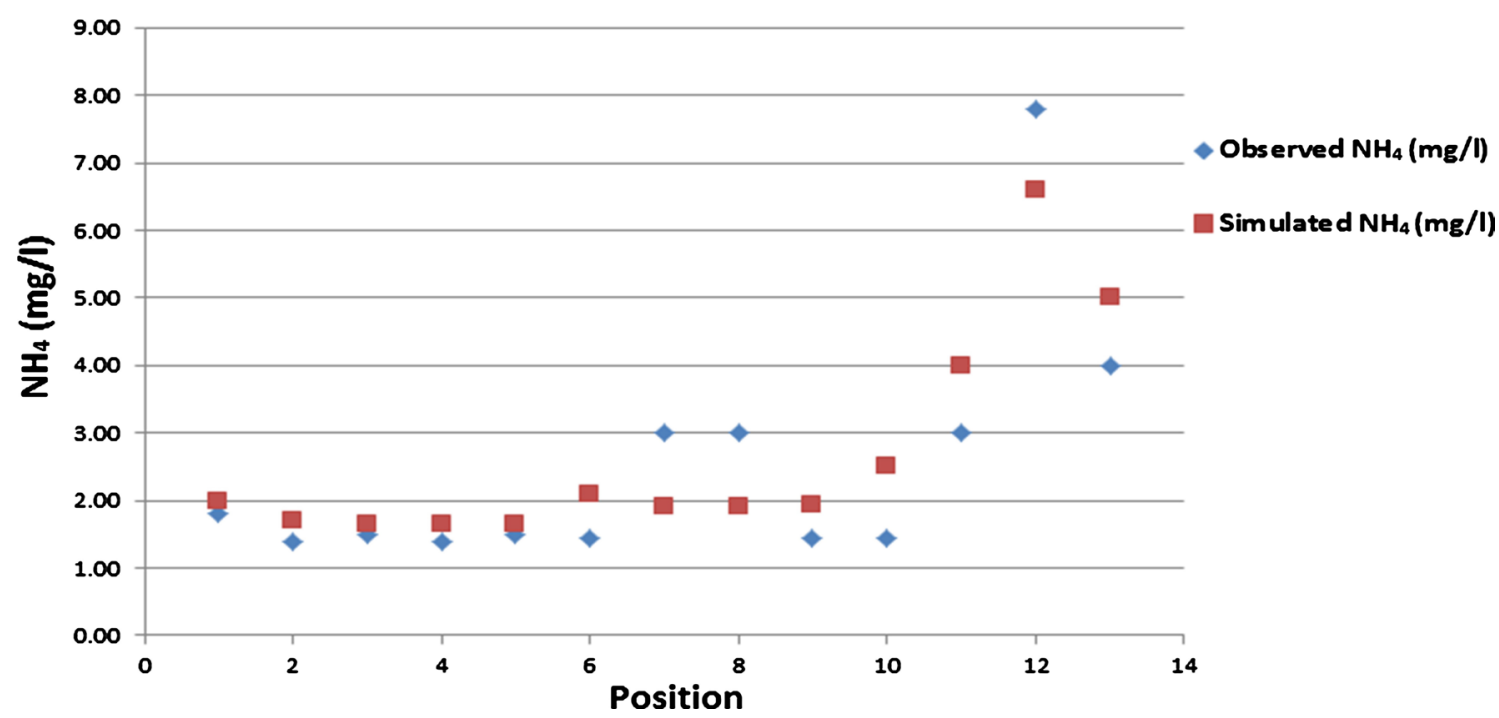

Figure 8. Edku Lake observed and simulated $\mathrm{NH}_{4}$, January 2016. 
From Figure 7 and Figure 8, it can be noted that the simulated $\mathrm{NH}_{4}$ concentrations are strongly correlated with the observed $\mathrm{NH}_{4}$ concentrations. The highest concentrations of ammonia were found at either the eastern or western areas of the lake during winter.

The increased concentrations of ammonia in the drainage water during winter can be attributed to the high ammonium application rate as fertilizers during this period of the year. However, $\mathrm{NH}_{4}$ concentration exceeds the permissible limits (maximum permissible $0.5 \mathrm{mg} / \mathrm{l}$ ) of the Egyptian national guidelines (law 48/1982).

\subsection{Model Validation}

\subsubsection{Modeling of BOD}

The model was validated by using 2017 dataset. Figure 9 shows the spatial distribution of BOD, while Figure 10 illustrates the lake simulated BOD with respect to the observed lake BOD during January 2017.

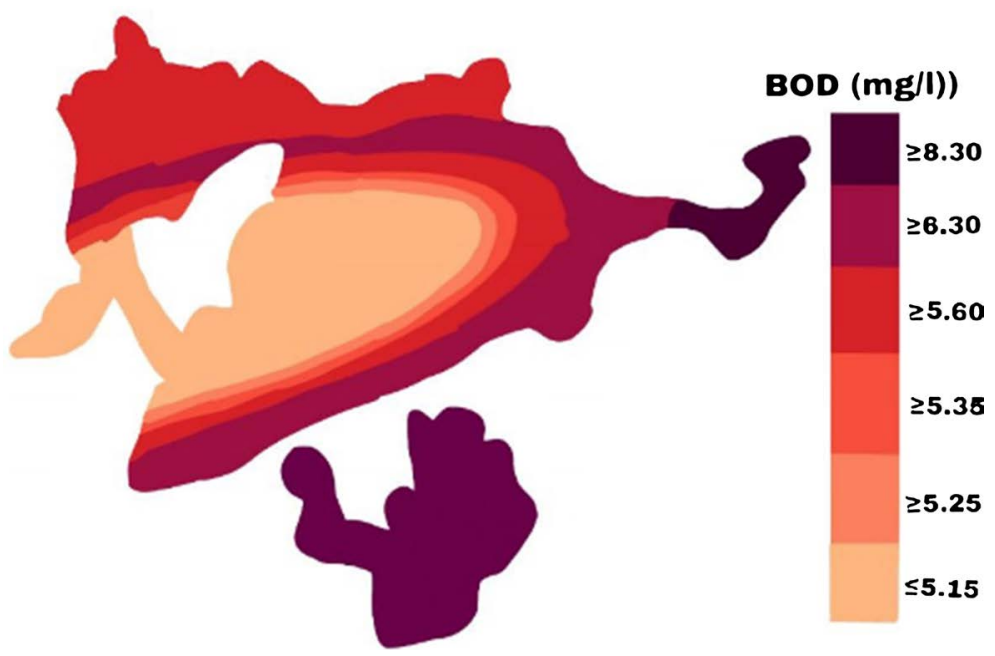

Figure 9. Edku Lake simulated BOD distribution, January 2017.

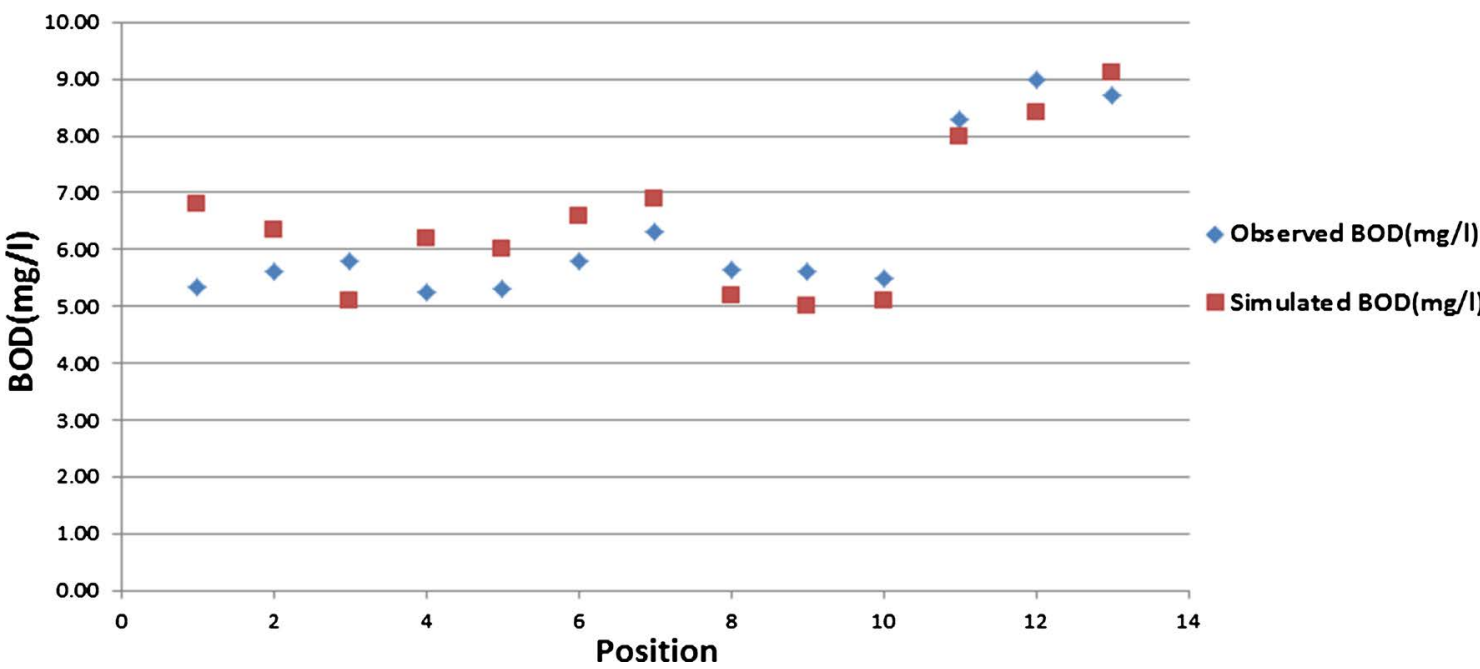

Figure 10. Edku Lake observed and simulated BOD, January 2017. 
From Figure 9 and Figure 10 it can be noted that the simulated BOD concentrations are strongly correlated with the observed BOD concentrations. In different lake sites, the most BOD concentrations exceed the allowable limits of Egyptian Governmental Law No. 48/1982 (BOD $\leq 10.00 \mathrm{mg} / \mathrm{l})$.

\subsubsection{Modeling of Phosphates $\left(\mathrm{PO}_{4}\right)$}

Figure 11 shows the spatial distribution of $\mathrm{PO}_{4}$ while Figure 12 illustrates the lake simulated $\mathrm{PO}_{4}$ with respect to the observed lake $\mathrm{PO}_{4}$ during January 2017.

A strong correlation between the simulated values of $\mathrm{PO}_{4}$ in Edku Lake is noted. The higher concentrations of phosphate are mostly due to the effect of drainage water enriched with phosphorous compounds.

\subsection{Management Scenarios}

To solve the lake water quality problems, six different water quality management scenarios have been proposed. These scenarios involved in applying primary drains treatment, secondary drains treatment, surface flow wetland for drains effluent, Biological biofilm activated with aerator for drains effluent, and constructing a

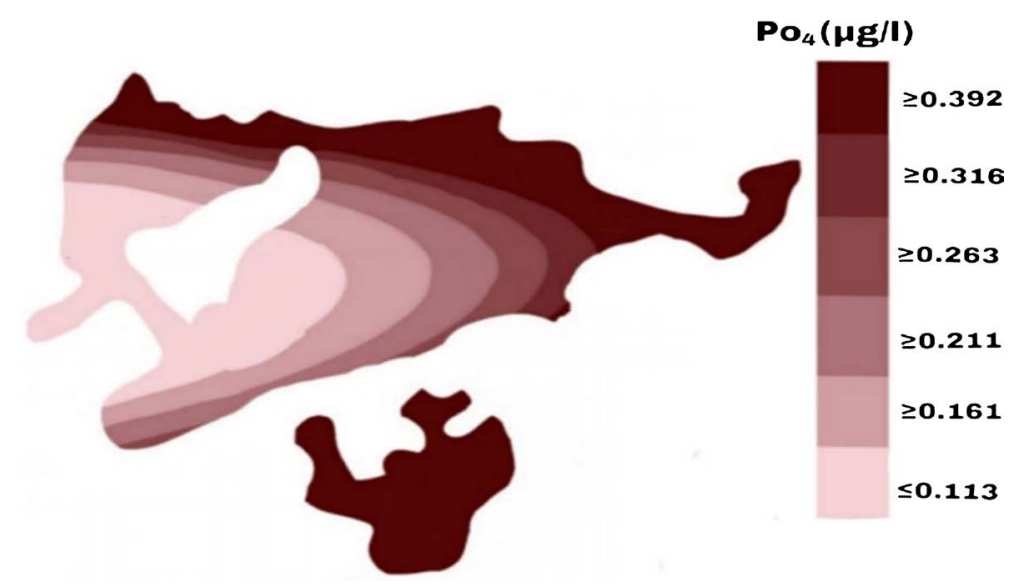

Figure 11. Edku Lake simulated $\mathrm{PO}_{4}$ distribution, January 2017.

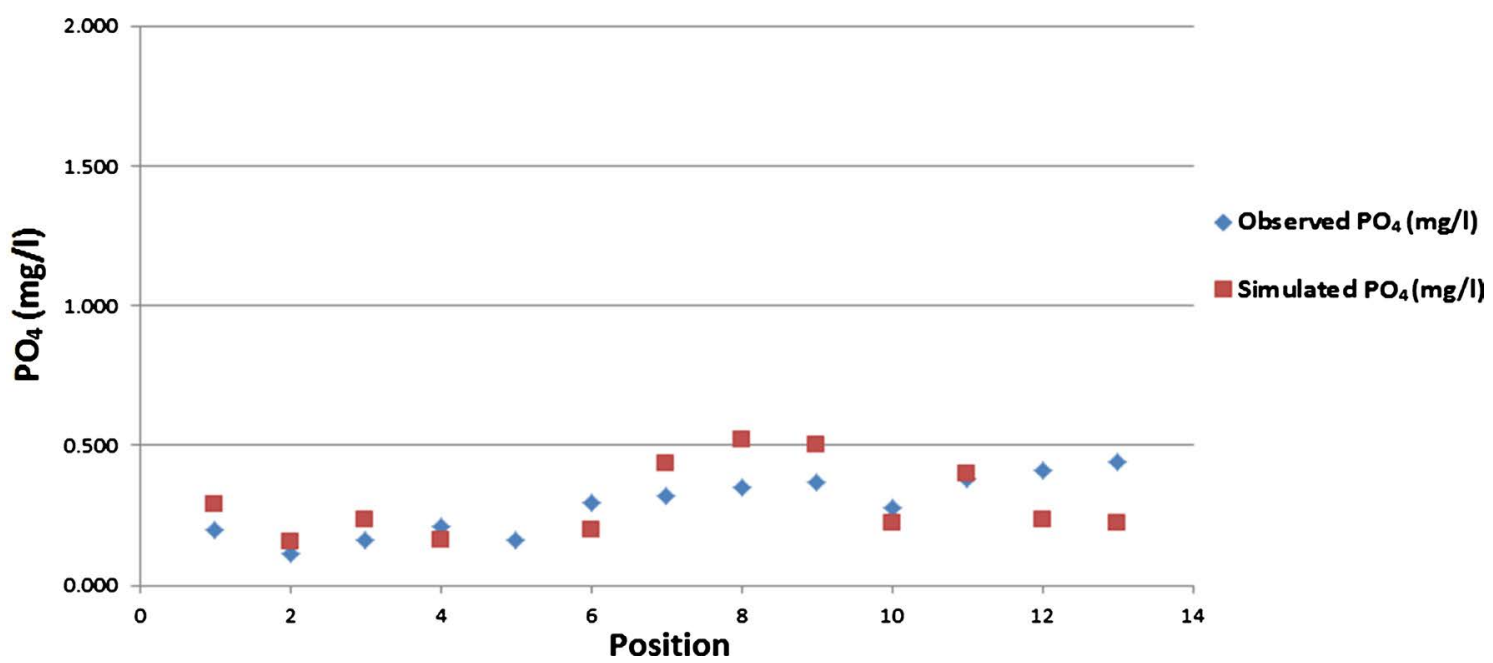

Figure 12. Edku Lake observed and simulated $\mathrm{PO}_{4}$, January 2017. 
new artificial inlet at the northern lake region. Figure 13 illustrates the lake water quality variables response under different hydrodynamic scenarios.

water quality variables response under different, January 2016

It can be noted from Figure 13 that there are variations in the lake response for water quality management scenarios. From water quality point of view, scenarios (4) and (6) appear the most effective scenarios for solving lake water quality problems.

\subsection{Multi Criteria Analysis}

Multi Criteria Analysis framework was developed based on four main criteria: technical, Environmental, Economic, Social and Community. Figure 14 shows the MCA framework criteria and indicators. These criteria were used for ranking the proposed water quality management scenario then find the most convenient water quality management scenario. MCA scoring system is formed based on the procedure developed by the USEPA (Okbah et al., 2006) as following:

$$
\text { Value }(x)=\sum_{i=1}^{n} W_{i}(x) \times C_{i}(x)
$$

where,

Value $(x)=$ Final value for alternative $x$.

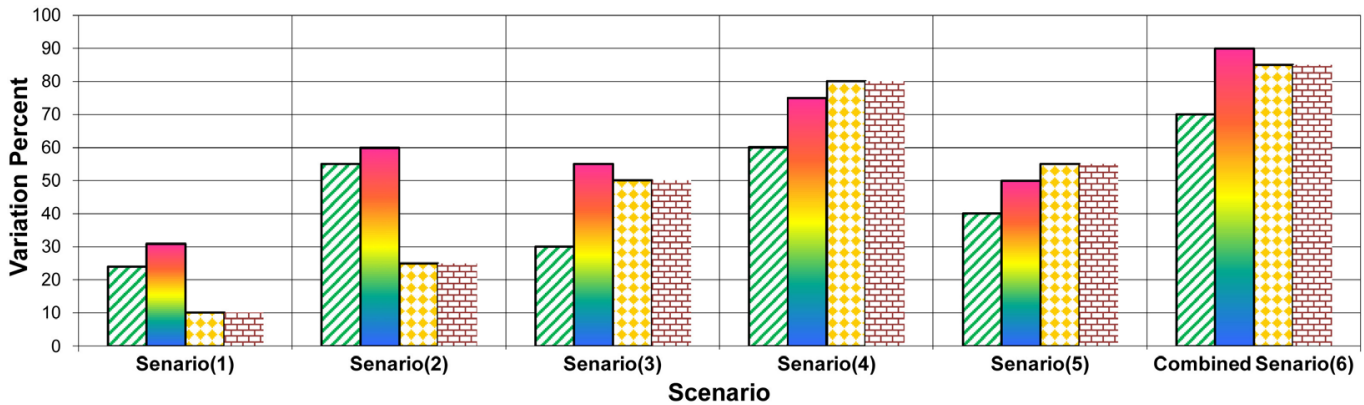

Figure 13. Edku Lake scenarios evaluation.

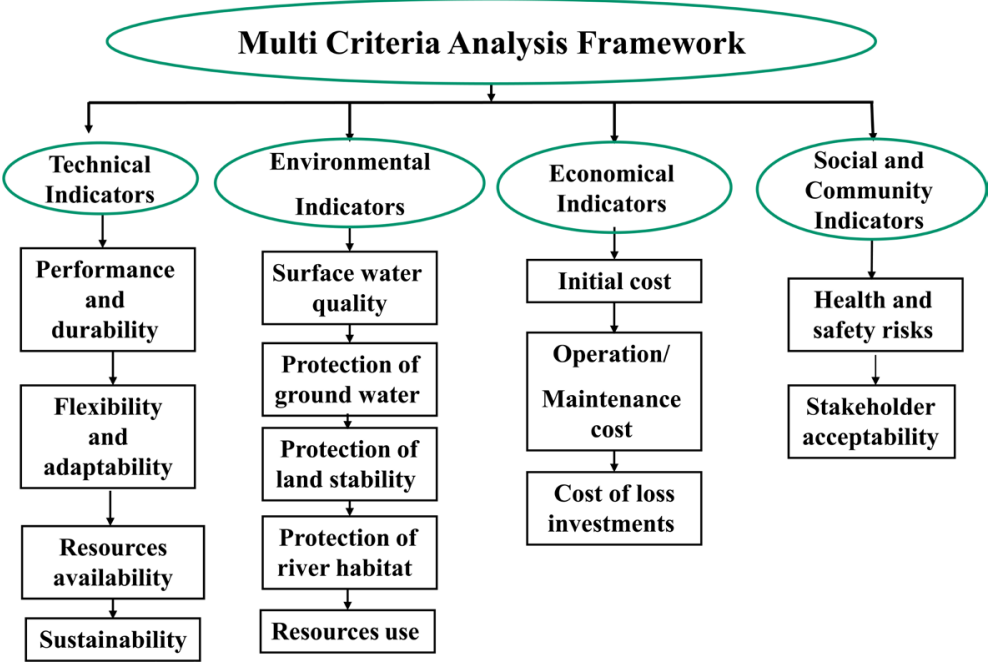

Figure 14. MCA framework criteria and indicators. 


\section{$W_{i}(x)=$ Weight of criterion $i$ for alternative $x$. \\ $C_{i}(x)=$ Score of criterion $i$ for alternative $x$.}

Generally, the weight of criteria and parameters were based on the gathered information and data from the international literature [4]. However, accesses weights were added to the most sensitive and effective criteria deal with the water quality, Health and safety risks, sustainability, and resource use. Figure 15 shows MCA final weight score for different water quality management scenarios.

It can be noted from Figure 15 for MCA Final weight scores that:

- MCA total weight score for various Edku Lake management scenario were found $50.0 \%, 56.8 \%, 64.8 .0 \%, 80.4 \%, 74.8 \%$, and $89.20 \%$ for scenario (1), (2), (3), (4), (5) and (6) respectively.

- The first scenario which involved in applying primary treatment technique for study area polluted drains has an overall low final weight score due to its limited influence in lake water quality improvement, restrictions on long run sustainability, and high probability health and safety risks increasing.

- The second scenario that proposed using secondary treatment instead of primary treatment has a relatively high final weight score compared with the first scenario but there are many noted limitation on applying this scenario especially with regard to technical and environmental indicators.

- In the third scenario, the proposed surface flow wetland technique has a relatively high technical and economic criteria weights but a relatively limited social criteria weight due to effect of stakeholder's acceptability, health and safety risks.

- It is noted from the fourth scenario evaluation that the application of biological biofilm activated for drains effluent has many convenient positive effects for all of the four main criteria. However, the thinking of combining this scenario with another suitable integrated scenario is essential for realizing the required optimum water quality management scenario.

- The fifth scenario that suggests constructing a new artificial inlet at the northern lake region has an overall obvious positive impact on the four main criteria compared with first three scenarios but in reality, applying this scenario as an individual scenario can lead to a noted increase in lake salinity.

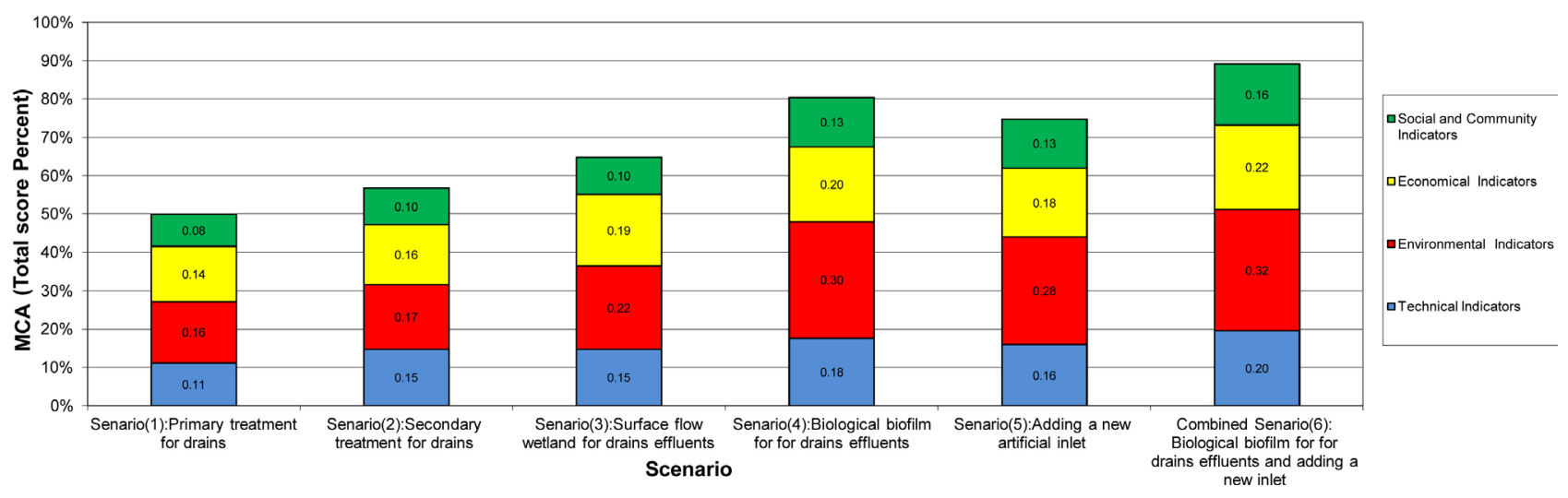

Figure 15. MCA final weight scores. 
- The sixth scenario that proposed applying a combination from both of the fourth and the fifth scenario together has the highest overall weight score, total technical and environmental weight scores. However, this scenario can be considered the most suitable scenario for Edku Lake water quality management.

\section{Conclusions}

- The present study proposed water quality management scenarios to assess and control Edku lake pollution by using Surface-Water Modeling System (SMS) hydrodynamic model.

- These proposed scenarios involved on primary, secondary, surface wetland, biological biofilm, adding a new artificial inlet.

- The developed Multi Criteria Analysis (MCA) framework, based on four main criteria: technical, environmental, economic, and social is very beneficial tool for the evaluation and ranking water quality management scenarios of Edku Lake.

- The last scenario that applying a combination biological biofilm technique and also adding a new artificial inlet can represent the optimum scenario.

\section{Funding}

This study was funded by Mohamed Ahmed Reda Hamed.

\section{Conflicts of Interest}

The authors declare no conflicts of interest regarding the publication of this paper.

\section{References}

[1] Abd El-Hamid, H.T., Hegazy, T.A., Ibrahim, M.S. and El-Moselhy, K.M. (2017) Assessment of Water Quality of the Northern Delta Lakes, Egypt. Journal of Environmental Sciences, 46, 21-34.

[2] Allam, M.N. and Allam, G.I. (2007) Water Resources in Egypt, Future Challenges and Opportunities. International Water Resources Association, 32, 205-218. https://doi.org/10.1080/02508060708692201

[3] Magdy, T.K., Safwat, H.S., Abd El-Halim, A.S., Gamal, M.S. and Montaser, M.H. (2008) Physicochemical Environment of Lake Edku, Egypt. Journal Aquatic Biology and Fisheries, 12, 119-132. https://doi.org/10.21608/ejabf.2008.1997

[4] SMS 6. Tutorials (1998) Environmental Modeling Research. Brigham Young University.

[5] Okbah, M.A. and El-Gohary, S. (2002) Physical and Chemical Characteristics of Lake Edku Water, Egypt. Journal Mediterranean Marine Science, 3, 27-39.

https://doi.org/10.12681/mms.246

Reemtsma, T. and M. Jekel, 2006. Organic Pollutants in the Water Cycle. Wiley-VCH, Weinheim, Germany. https://doi.org/10.1002/352760877X

[6] SMS 7. Tutorials (2000) Environmental Modeling Research. Brigham Young University. 